\title{
Society 留eproxts.
}

\section{NEW YORK NEUROLOGICAL SOCIETY.}

\author{
Stated Meeting, Feb. 2, I897. B. Sachs, M.D., President.
}

\section{CASE SIMULATING SYRINGOMYELIA.}

I)r. Graeme M. Hammond presented a lacly who, ten years ago, after an illness sinilar to an attack of la grippe, began to have loss of sensation to pain and temperature in left arm. During these ten years the symptoms had extended to the left leg, trunk and side of the face. Dr. Hun had carefully examined her, and had made a diagnosis of syringomyelia. When first seen by the speaker the symptoms had been certainly very like those of that disease-absolute insensibility to temperature and pain, with perfect preservation of the sense of touch. But the absence of paralysis and contractures, the normal electrical contractility and the fact that the other side was not affected argued against this diagnosis. In addition to this, there were several symptoms of neurasthenia-insomnia, noises in the ears and confusion of ideas. It had occurred to him that the case might be of neurasthenic origin, and acting upon this theory, she had been .given bromides, together with as much mental impression as possible. The result had not been disappointing. Now, the pain and temperature sense had returned in the face and trunk. The sensation of pain and temperature were not fully restored in the left hand or in the trunk, but were decidedly improved. She had never been told what the symptoms of the disease were, so that there could have been no suggestion.

Dr. M. Allen Starr suggested that there might possibly be a small area in the cord of disease that had started the symptoms and given the "suggestion," thus making the case a complex one.

\section{CEREBELLAR ATAXIA.}

Dr. George W. Jacoby presented a little girl of nine years -a typical case of cerebellar ataxia. In this case there was no heredity. The father married his own niece, but with this exception the family history was negative. This child did not walk until three years of age, and was generally backward, 
both mentally and physically. Examination showed marked ataxia in both upper and lower extremities. When unobserved, the child exhibited constant choreiform movements of the head and upper extremity. When walking the body was thrown forward and the head somewhat backward; the legs were spread far apart, and there was a constant tendency to falling. In reaching for an object, there was an uncertainty of movement. The eyes showed a slight fixation nystagmus at times. There were no changes in the optic nerve. The reflexes were very much exaggerated: There was no deformity in the lower extremities. He felt that the case should be looked upon as a congenital defect of the cerebellum.

Dr. Joseph Collins endorsed the last statement of Dr. Jacoby. He had looked into the literature of the subject, and had been impressed with the necessity of differentiating between hereditary and familiar changes. In a case that he had had there had been no hereditary history whatever, nevertheless a younger child, who had died about the end of the second year, and was described as having had from its birth "St. Vitus' dance" and other symptoms, had probably suffered from the same disease.

\section{DEMONIACAJ, POSSESSION.}

Prof.Wm.James, of Harvard University, delivered an address on this subject. He said that our knowledge of altered personality had made rapid strides in recent years. We had the transient altered personality of epileptic insanity, and certain dream states that had been described under the name of "ambulatory automatism"-the subject going from home and returning after an interval of, perhaps, weeks, with the memory of what had happened during his wanderings utterly effaced. In one case that he had treated, hypnotic suggestion had brought back the memory of the wanderings. There was still another altered personality, that called " spirit control." This was connected with demoniacal possession. The obsolescense of public belief in the possession by demons was a very strange thing in Christian lands, when one considered that the sacred books of our religion were full of this belief. Every land and every age had exhibited the facts on which this belief was founded. The particular form of supernatural origin varied with the traditions and popular beliefs of each country. When the Pagan gods became demons, after the triumph of Christianity in Europe, all possession was looked upon as diabolic. It was now replaced by the thoroughly optimistic belief that changed personality is the spirit of a human being coming to bring messages of comfort from the sunny land. The unconsciousness, the speaker said, was usually ushered in by a more or 
less pronounced convulsion-the person's character became entirely changed in its attitude, voice and manifestations. After an hour or two, the manifestation passed off, leaving a complete amnesia behind of everything that had occurred. During the intervals of the attacks the person was entirely well. The condition was, therefore, entirely distinct from any form of insane delusion. Mr. Percival Lowell had reported that in Tokio, Japan, there were a number of persons who cultivated the power of passing into trances. In China there was a widespread belief that possession by gods and spirits could take place. Mr. Nevins, a missionary in China, had reported a number of cases of demoniacal possession. In Japan there was a curious superstition that the person afflicted was not affected by a demon but by a fox. In India instances of this kind were extremely common.

The speaker said that the witcheraft delusion had been explained in various ways, but to him witches were not neuropathic persons, but the accusers were. He had carefully examined the witchcraft trials, and had found that it started in some demon disease in the neighberhood. These "demon diseases" were very common in those days, being any functional neuropathic disease. If there were no obvious physical disorder, and the symptoms did not yield readily to the usual medical treatment, the case was considered to be one of demon disease. Professor James quoted from a book written in 1602, by a French magistrate, in which a detailed description was given of a girl possessed with five demons, and the manner in which they came out of her mouth and ran about the fire two or three times before disappearing. He said that these descriptions reminded one of the classical hysterical attack-the lump in the throat, the convulsive seizures, etc. The cases appeared to be examples of imitative hysteria, patterned after the case existing at that time. Differences in the different countries, of course, came from the differences in the psychological climate. Many interesting reports had been published of late years of epidemics of chorea, supposed to have resulted from imitation. These epiclemics had been known to lasst for months or even years. An interesting case of demoniacal possession in France, in I863, had been reported by Dr. Augustin Constance, in Savoy. A similar epidemic had been reported in Italy. The epidemic in France began with hysteria among certain children, and was propagated by example until at last a very large number of persons was attacked with all the symptoms of demoniacal possession. When Dr. Constance arrived upon the scene, a year after the breaking out of the epidemic, I ro persons were affected. He examined a number of these individuals, and found them to be suffering from hysterical attacks, brought on by suggestion. The patients were wisely sent away to other villages, and in that way he broke up the epidemic. 
Hystero-demonopathy is the name given to these symptoms. No one could fail to recognize in these attacks the analogy to the performances of the numerous spiritualistic mediums of the present time. It would be strange, incleed, if a phenomenon which had played such a large part in history should have died out without leaving anything in its place. Medical men should learn from all this a certain lesson, $i$. $c$., that as our views had become optimistic, instead of pessimistic, the whole thing had become harmless. We live in a day when there is much alarmist writing in psychopathy about degeneration, and the alarming signiticance of all sorts of symptoms and signs, so that there is danger of drawing the line of health too narrowly.

Dr.C.A. Herter said that the idea of connecting the powers of moclern spiritualistic mediums with the peculiar forms of clemoniacal possession which occurred in former years, was a most interesting one. This fact had been brought out most interestingly and impressively in the address. He had been much interested in the gradual change from the damaging charaçter to the comparatively beneficent character of these phenomena.

Mr. Martin said that it seemed to him rather remarkable that the suggestions which occurred to the possessed person related almost entirely to ethical matters, or religious subjects. A large portion of the recorded cases that he had met with referred to the possession by devils who were leading the person astray, or into inmorality. He would like to ask if Professor James liad observed the same thing.

Professor James replied that it was a law of the secondary consciousness that it took the religious form.: He had no explanation to offer, however, of this law. It was a singular fact that involuntary writing was apt to take the spiritualistic form. This would occur in the case of persons who had no intellectual hospitality for that view, and who had not been exposed to spiritualistic influences. Spirits, religious truths and philosophical discourses were the staple of these communications.

Dr. Mary Putnam Jacobi said that as in so many cases of melancholia the grief was about having sinned against the Holy Ghost, even in persons who had had no religious or Calvinistic instruction, she would like to ask if Professor James considered it an example of the phenomena just spoken of. She would also like to ask his opinion of an essay that had been published, entitled, "Were the Salem witches entirely guiltless?" According to this essay, although these witches were not possessed by devils, they were abandoning themselves to impulses coming from the lower structures of their naturesthe result of ancestral influences.

Professor James replied that he did not think the delusions of melancholia had anything to do with the subject under dis- 
cussion. The sin against the Holy Ghost was only an endeavor to explain the grief which was left. Regarding the essay by Professor Barrett Wendell, to which allusion had been made, he would say that at the time of the witcheraft belief there were certainly persons attempting to do what they could by diabolical aid, but in all probability they formed a very small part of it. In Salem, the girls from whom the accusations emanated had been having hypnotic seances from a West Indian slave, who was herself pratically insane. They passed then into such a condition that they were accused of witchcraft, and were tried under such circumstances as to impress them powerfully by suggestion. From what we know of imitative hysteria, the whole matter was entirely explicable on that basis, without any supposition of guilt upon the part of these children. It was a suggestive epidemic of a semi-hysterical nervous disorder.

Dr. C. L. Dana said that the speaker had made quite clear the relation of trance to demoniacal possession of old, but he would like to know how widespread was this condition now. He knew that about fifteen years ago spiritualism had been immensely prevalent in the Eastern states. Ir the condition had continued to exist and spread, there was certainly much more in the United States to-day than in civilized countries several hundred years ago.

Professor James replied that it would be diffictilt to answer this question statistically, as we had no trustworthy statistics. We knew, however, that at the present time there were many "faith healers."

Ueber Familiäre SPASTische Spinalparalyse. [Concerning the Family Form of Spastic Spinal Paralysis.] Deutsche Zeitschrift für Nervenheilkunde, Band IX., Heft 3 u. 4. By H. Hochhaus.

Three cases of spastic spinal paralysis, occurring in one family, are reported. One child of seventeen years in this family was sound. The disease began in the second year of life, and by the sixth year had acquired great intensity. After this age the symptoms remained stationary in one case, improved in another, and increased in a third. In all three cases spastic paresis of the lower extremities, with exaggeration of the reflexes and foot clonus, without disturbance of sensation or of the vesical and rectal functions, was observed. In one case distinct atrophy of the legs was noticed. No cause could be discovered; birth had not been premature or difficult, nor were there signs of early meningitis. Tuberculosis was hereditary in the family of the mother. The limitation of the spastic paresis to the lower limbs during many years indicated some disease of the pyramidal tracts in their lower portion, developing in imperfectly formed fibres.

In none of these cases were any symptoms observed which nust of necessity be attributed to a cerebral lesion. Spiller. 